\title{
Support for School-Based Obesity Prevention Efforts: Attitudes among Administrators at Nationally Representative Samples of US Elementary Schools
}

\author{
Lindsey Turner, PhD, Sandy J. Slater, $\mathrm{PhD}$, $^{1,2}$ and Frank J. Chaloupka, PhD 1,3
}

\section{Abstract}

Background: With the continued threat of childhood obesity, many public health intervention efforts focus on school settings. The current study sought to document administrator attitudes regarding obesity and interest in improving relevant school practices (i.e., nutrition and physical activity) in elementary schools.

Methods: Mail-back surveys were used to gather data from public and private elementary schools during the 2006-2007, 20072008, 2008-2009, and 2010-2011 school years. In each year, a different set of items pertaining to administrator attitudes was included. Numbers of responding schools annually ranged from 259 to 336 private schools, and from 578 to 748 public schools.

Results: The vast majority of elementary school administrators $(>90 \%)$ agreed that schools can play a role in addressing childhood obesity, physical education improves a variety of academic outcomes, and they were interested in improving practices at their school. Concern about childhood obesity and perceiving that schools can play a role in addressing obesity were both associated with more interest in improving school practices. However, only one-third of administrators agreed that parents were interested in participating in improving nutrition and physical activity practices, suggesting opportunities for efforts to improve collaboration.

Conclusions: Administrators are generally very supportive of school-based efforts to improve nutrition and physical activity practices and see the value in doing so. Given the amount of time children spend in school, schools are an essential venue for efforts to address childhood obesity.

\section{Introduction}

$\Delta$ s of $2009-2010,32.6 \%$ of children ages $6-11$ years, those typically in elementary school, were overweight or obese. ${ }^{1}$ Recommendations from the Institute of Medicine (IOM) emphasize the importance of school-based obesity prevention efforts, ${ }^{2}$ and schools are a key level in social-ecological models that identify factors involved in obesity ranging from the intrapersonal level (e.g., genetics) to the broader environment (e.g., built environment characteristics). ${ }^{3-5}$ Ecological models have long acknowledged the importance of multiple influences on human behavior, ${ }^{6-8}$ and schools are a behavioral setting that plays an essential role in shaping children's obesity- relevant behaviors (i.e., food intake and physical activity). "Organizational factors" $"$ such as schools are conceptually important for understanding obesity-relevant behaviors, and, indeed, accumulating research demonstrates that many practices and policies in schools are linked with weight outcomes such as BMI. ${ }^{9-12}$

Theoretical models that were initially developed to understand behavior change among individuals can also inform efforts to understand factors contributing to change in organizational practices. Administrators are key stakeholders in school-based public health efforts, and, as such, understanding their receptiveness to change, as well as other attitudinal factors, is important for school-based obesity prevention efforts. Furthermore, it has been

\footnotetext{
'Institute for Health Research and Policy, and ${ }^{2}$ Department of Health Policy and Administration, School of Public Health, University of Illinois at Chicago, Chicago, IL.

${ }^{3}$ Department of Economics, University of Illinois at Chicago, Chicago, IL.
} 
suggested that school administrators are "microenvironmental agents" who serve as leverage points for effecting changes in the school environment. ${ }^{13,14}$

At the individual level, theoretical models that examine individuals' willingness to adopt preventive health behavior include long-standing and well-studied efforts to understand the interplay between attitudes and behaviors. For example, the Theory of Reasoned Action ${ }^{15}$ and its extension as the Theory of Planned Behavior ${ }^{16}$ both emphasize the importance of behavioral intentions (plans to engage in change), as well as attitudes such as the perceived value of the behavior, perceived behavioral control, and subjective norms (i.e., perceptions of what others think of the behavior). As applied to nutrition and physical activity (PA), such attitudes could involve perceptions of what other stakeholders believe (i.e., parent support), perceived importance or threat of childhood obesity, and attitudes about whether schools are an appropriate venue for prevention, as well as how much of an impact schools can have on children's health. Similarly, other models such as the Health Belief Model $^{17,18}$ emphasize the importance of perceived severity of, and susceptibility to, a certain condition (i.e., childhood obesity). Given the importance of theory in understanding health practices, the current study examined a variety of attitudinal factors among school administrators, which were selected based on theoretical models.

Despite increasing attention to obesity-prevention efforts in the school setting, few studies have assessed administrator beliefs, attitudes, or perceptions among large national samples of administrators. Qualitative research among administrators and teachers at five Boston middle schools that participated in the Planet Health ${ }^{19}$ intervention (addressing nutrition and PA) indicated widespread support for improving school practices. ${ }^{20}$ Participants also noted that classroom nutrition education interventions were not consistent with the practices in the lunch program (e.g., serving fried potatoes), and that difficulty in changing the school meals was a key barrier to promoting healthier behavior. ${ }^{20}$

Survey research among a large group of middle school teachers $(n=490)$ and parents of middle school students $(n=350)$ in Minnesota documented agreement regarding the importance of good nutrition practices in schools. ${ }^{21}$ Teachers acknowledged that nutrition affects readiness to learn (92\% agreed), that a healthy school environment is important (97\%), and that teen eating habits should be a school priority ( $72 \%$ ); however, few teachers believed that schools give adequate attention to nutrition (31\%). The work was done in $1999,{ }^{21}$ prior to the federal wellness policy mandate ${ }^{22}$ and the dramatic increase in research and policy attention regarding childhood obesity that occurred in the first decade of the $2000 \mathrm{~s}$; thus, attitudes may have changed since that time.

In 2007, during the early stages of adoption of the federal wellness policy mandate, Action for Healthy Kids and other research partners surveyed 2400 stakeholders relevant to school wellness, including school superintendents, school board members, principals, teachers, and food and nutrition staff. ${ }^{23}$ Results demonstrated discrepancies in stakeholder perceptions regarding a variety of topics. For example, $80 \%$ of superintendents and $90 \%$ of food service professionals believed that schools were already providing children with appealing and healthy beverages and limiting unhealthful options, whereas only one-third of teachers, parents, and community health professionals agreed. ${ }^{23}$ Approximately half of superintendents and principals agreed that schools were providing quality physical education (PE), whereas $80 \%$ of school physical education professionals believed that improvements were needed. ${ }^{23}$ Such research highlights the importance of engaging a variety of stakeholders in understanding areas in need of change and in marshalling cooperative efforts to promote such change.

The current study used nationally representative data from large samples of public and private elementary schools in the United States during the 2006-2007, 20072008, 2008-2009, and 2010-2011 school years to examine school administrator attitudes regarding childhood obesity and relevant behaviors.

\section{Methods}

\section{Procedure}

Data on administrator attitudes were gathered via mailback surveys among nationally representative samples of public and private elementary schools in the contiguous United States. Surveys were mailed to school principals during the spring (second half) of each school year, from 2006-2007 to 2010-2011 (data from 2009-2010 are not used here because no attitude items were included on that survey). An honorarium of $\$ 100$ was offered to the school or survey respondent for returning the survey. Reminders were made by telephone, e-mail, and mailings. The Institutional Review Board at the University of Illinois at Chicago approved the study protocol and survey materials with a waiver of written documentation of informed consent, as consent was implied by return of the survey.

\section{Sampling and Weighting}

School samples for each year were developed at the Survey Research Center at the Institute for Social Research at the University of Michigan, based on public-use datasets from the National Center for Education Statistics (NCES). Because elementary schools vary in grade level (e.g., kindergarten to grade 2, grades 1-6), all schools were required to include a $3^{\text {rd }}$ grade. Weights were developed to allow for inference to elementary schools across the United States; separate weights were developed for public and private schools. After data collection was complete, weights were adjusted for potential school nonresponse bias.

\section{Participants}

Demographic characteristics of schools in the sample are presented in Table 1. School characteristics were obtained 


\begin{tabular}{|c|c|c|c|c|c|}
\hline & \multicolumn{2}{|c|}{ Public } & \multicolumn{2}{|c|}{ Private } & \multirow[b]{2}{*}{$p$ value $^{c}$} \\
\hline & $n$ & $(\%)^{b}$ & $n$ & $(\%)^{b}$ & \\
\hline \multicolumn{6}{|l|}{ Region } \\
\hline South (ref) & 896 & (34.6) & 391 & $(29.9)$ & \\
\hline West & 610 & $(23.1)$ & 238 & $(19.9)$ & \\
\hline Midwest & 650 & $(25.4)$ & 336 & $(26.4)$ & \\
\hline Northeast & 409 & $(16.9)$ & 216 & $(23.8)$ & 0.0051 \\
\hline \multicolumn{6}{|l|}{ Locale } \\
\hline Urban (ref) & 692 & $(31.3)$ & 512 & $(43.3)$ & \\
\hline Suburb & 861 & (30.3) & 499 & $(40.8)$ & \\
\hline Town & 344 & $(\mathrm{II} .7)$ & 76 & $(7.3)$ & \\
\hline Rural & 663 & (26.7) & 94 & $(8.6)$ & $<0.0001$ \\
\hline \multicolumn{6}{|l|}{ School size } \\
\hline $\begin{array}{l}\text { Large (>62I students; } \\
\text { ref) }\end{array}$ & 724 & $(21.6)$ & 178 & $(10.5)$ & \\
\hline $\begin{array}{l}\text { Medium ( } 45 \text { I to } 62 \text { I } \\
\text { students) }\end{array}$ & 826 & $(29.6)$ & 224 & $(15.0)$ & \\
\hline Small ( $<45$ I students) & 1015 & $(48.7)$ & 779 & $(74.5)$ & $<0.0001$ \\
\hline $\begin{array}{l}\text { Student race/ethnicity, } \\
\text { percentage of white } \\
\text { students (mean, SE) }\end{array}$ & \multicolumn{2}{|c|}{$(55.3,1.3)$} & \multicolumn{2}{|c|}{$(72.7,1.3)$} & $<0.0001$ \\
\hline $\begin{array}{l}\text { Percentage of students } \\
\text { eligible for free/reduced- } \\
\text { price meals (mean, SE) }\end{array}$ & \multicolumn{2}{|c|}{$(5 \mathrm{I} . \mathrm{I}, 0.8)$} & \multicolumn{2}{|c|}{$\mathrm{n} / \mathrm{a}$} & $\mathrm{n} / \mathrm{a}$ \\
\hline
\end{tabular}

aSample size is unweighted; percentages are weighted to the school level.

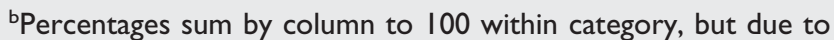
rounding some may not sum to exactly $100 \%$.

${ }^{c} p$ value associated with chi-squared test to compare public versus private schools.

dNot available for private schools; this variable not included as covariate in subsequent analyses.

ref, reference category; SE, standard error.

from the NCES datasets ${ }^{24}$ (Common Core of Data for public schools and Private School Survey for private schools) for the corresponding year of data collection. Data on the percentage of students eligible for free or reducedprice meals (FRPM) was available only for public schools, but not for private schools. Information on the role of the survey respondent was gathered, but no additional personal details (e.g., age, gender) were gathered from respondents. In many cases, multiple respondents contributed to the completion of the survey, which included items on food and nutrition practices, PE, and other school wellness topics.
In each year, the recruitment sample included approximately 1070 public schools and 400 private schools. Sampled schools that had closed or did not include a $3^{\text {rd }}$ grade were considered ineligible and were excluded from response rate calculations. The number of responding schools and response rates across the 4 years (2006-2007, 2007-2008, 2008-2009, and 2010-2011) were as follows, respectively: for private schools, $n=259(66.2 \%), n=336$ (84.4\%), $n=297(76.2 \%)$, and $n=289(73.4 \%)$; and for public schools, $n=578(54.6 \%), n=748(70.6 \%), n=641$ $(61.8 \%)$, and $n=598(57.4 \%)$.

\section{Variables}

The survey items were developed by researchers based on reviews of the literature, other relevant work, and development of conceptually relevant attitude factors. Due to limited space on the survey instrument, questions were replaced and/or modified over the study period. Thus, each item appeared for 1 year only, and examination of potential change in attitudes over time is not possible with these data. Exact wording of all survey items (and year of data collection) is given in Table 2. Respondents were asked to indicate the degree to which they agreed with each statement, with response options of $1=$ strongly disagree, $2=$ disagree, $3=$ agree and $4=$ strongly agree.

\section{Analyses}

Analyses were conducted in STATA/SE (version 12.0, StataCorp, College Station, TX, 2011) with the svy command to account for sampling stratum and for clustering of schools within districts and states. To control for school characteristics, statistical tests for differences in attitudes by school type involved examining the odds ratio for school type (public versus private) in logistic regressions that controlled for school demographic characteristics. Each characteristic (e.g, region) was entered as a set of dummy-coded variables (see Table 1 for coding and referent categories).

\section{Results}

\section{Sample Characteristics}

Demographic characteristics of the schools from which surveys were returned did not vary significantly across years (as tested by chi-squared analysis, all $p$ values $>$ 0.05 ); however, the characteristics of responding public schools differed significantly from those of private schools. As shown in Table 1, private schools were more likely to have predominantly white student populations, were more likely to be located in urban or suburban areas, and had smaller student enrollments. They were also fairly evenly distributed across the four contiguous census regions of the United States, whereas public schools had slightly higher representation in the South as compared to the Northeast. 


\begin{tabular}{|c|c|c|c|c|c|c|}
\hline & \multicolumn{2}{|c|}{ All schools } & \multicolumn{2}{|c|}{ Public schools } & \multicolumn{2}{|c|}{ Private schools } \\
\hline & $\%$ & $(\mathbf{S A}+\mathbf{A})$ & $\%$ & $(\mathbf{S A}+\mathbf{A})$ & $\%$ & $(\mathbf{S A}+\mathbf{A})$ \\
\hline I am concerned about children at this school being overweight ${ }^{\mathrm{a}}$ & 76.3 & $(20.9+55.4)$ & 78.0 & $(21.3+56.7)$ & 64.7 & $(18.4+46.3)$ \\
\hline $\begin{array}{l}\text { I am interested in encouraging students at this school to } \\
\text { consume more nutritious foods and beverages }{ }^{\mathrm{a}}\end{array}$ & 98.3 & $(43.9+54.4)$ & 98.4 & $(43.4+55.0)$ & 97.6 & $(47.0+50.6)$ \\
\hline $\begin{array}{l}\text { I am interested in encouraging students at this school to get } \\
\text { more exercise and physical activity than they do now }\end{array}$ & 94.7 & $(43.7+51.0)$ & 95.6 & $(44.3+51.3)$ & 89.3 & $(39.8+49.5)$ \\
\hline $\begin{array}{l}\text { Parents of students at this school have expressed an interest in } \\
\text { participating in improving nutrition practices at school }{ }^{\mathrm{b}}\end{array}$ & 35.9 & $(4.6+31.3)$ & 34.5 & $(4.5+30.0)$ & 50.9 & $(9.6+41.3)$ \\
\hline $\begin{array}{l}\text { Parents of students at this school have expressed an interest in } \\
\text { participating in improving physical activity practices at school }\end{array}$ & 36.5 & $(3.9+32.6)$ & 35.5 & $(3.8+31.7)$ & 42.0 & $(4.3+37.7)$ \\
\hline $\begin{array}{l}\text { Keeping students physically active helps them to perform better } \\
\text { in other classroom activities and academics }{ }^{\mathrm{a}}\end{array}$ & 99.0 & $(63.4+35.6)$ & 99.0 & $(62.5+36.5)$ & 98.8 & $(69.2+29.6)$ \\
\hline $\begin{array}{l}\text { High-quality physical education can enhance student } \\
\text { concentrationc }^{c}\end{array}$ & 97.1 & $(69.1+28.0)$ & 97.3 & $(70.3+27.0)$ & 96.7 & $(62.0+34.7)$ \\
\hline $\begin{array}{l}\text { High-quality physical education decreases student discipline } \\
\text { problems }{ }^{c}\end{array}$ & 94.2 & $(50.9+43.3)$ & 94.8 & $(52.5+42.3)$ & 90.5 & $(40.7+49.8)$ \\
\hline High-quality physical education improves academic performance ${ }^{c}$ & 96.2 & $(57.2+39.0)$ & 96.6 & $(59.1+37.5)$ & 94.0 & $(44.9+49.1)$ \\
\hline $\begin{array}{l}\text { Schools can play a role in addressing the problem of childhood } \\
\text { obesity }^{\mathrm{a}}\end{array}$ & 95.7 & $(40.8+54.9)$ & 95.6 & $(41.2+54.4)$ & 96.7 & $(38.5+58.2)$ \\
\hline Schools can play a role in addressing childhood obesity ${ }^{d}$ & 97.6 & $(53.1+44.5)$ & 97.7 & $(52.9+44.8)$ & 96.8 & $(54.3+42.5)$ \\
\hline
\end{tabular}

a Surveyed in 2006-2007, $n=578$ public schools, 259 private schools.

bSurveyed in 2007-2008, $n=748$ public schools, 336 private schools.

'Surveyed in 2008-2009, $n=641$ public schools, 297 private schools.

dSurveyed in 2010-20I I, $n=598$ public schools, 289 private schools.

SA, strongly agree; A, agree.

\section{Respondent Characteristics}

The last page of the survey included blank lines where respondents were asked to write their role at the school, as well as the role of any other individuals who contributed to the survey. At most schools (64.6\%), only one individual completed the survey; at $31.7 \%$ of schools, two individuals completed the survey, and at $3.7 \%$ of schools, three or more individuals contributed to the survey. At most schools $(88.8 \%$ of public schools, and $87.4 \%$ of private schools), the survey was completed by a principal or assistant principal, or staff with another variant of an administration title (e.g., school director, head of school). Where the respondent was not an administrator, the roles most commonly reported were: Secretary/office manager, cafeteria manager, PE teacher, or nurse. Given that the majority of surveys were completed by administrative staff, for parsimony, hereafter respondents are referenced as "administrators."

\section{Administrator Attitudes}

Table 2 presents the percentage of administrators agreeing with each item, as well as the breakout of "strongly agree" and "agree" within that total percentage.

As shown in Table 2, the vast majority of administrators ( $>90 \%$ ) agreed or strongly agreed with all of the attitudes assessed, with the exception of the attitudes regarding perceived parent interest in participating in improving nutrition practices and PA practices at school, which were each endorsed by approximately one-third of respondents, and concern about student overweight, which was endorsed by approximately three-fourths of respondents.

A series of multivariate logistic regression models was used to examine whether strong administrator agreement with attitude items varied by school demographic characteristics. Due to the frequency of responses - with a majority of respondents endorsing either "agree" or "strongly agree" for most of the items - to meet the requirements for adequate variability in the outcome variable for logistic regression analyses, the outcome variables were collapsed to examine "strong agreement" (i.e., a binary variable of $1=$ "strongly agree" versus $0=$ "agree," "disagree," or "strongly disagree"). However, because there was less administrator agreement with the two items regarding perceived parent interest in improving school practices than for the other topics, these two regression models predicted any agreement, either "strongly agree" 


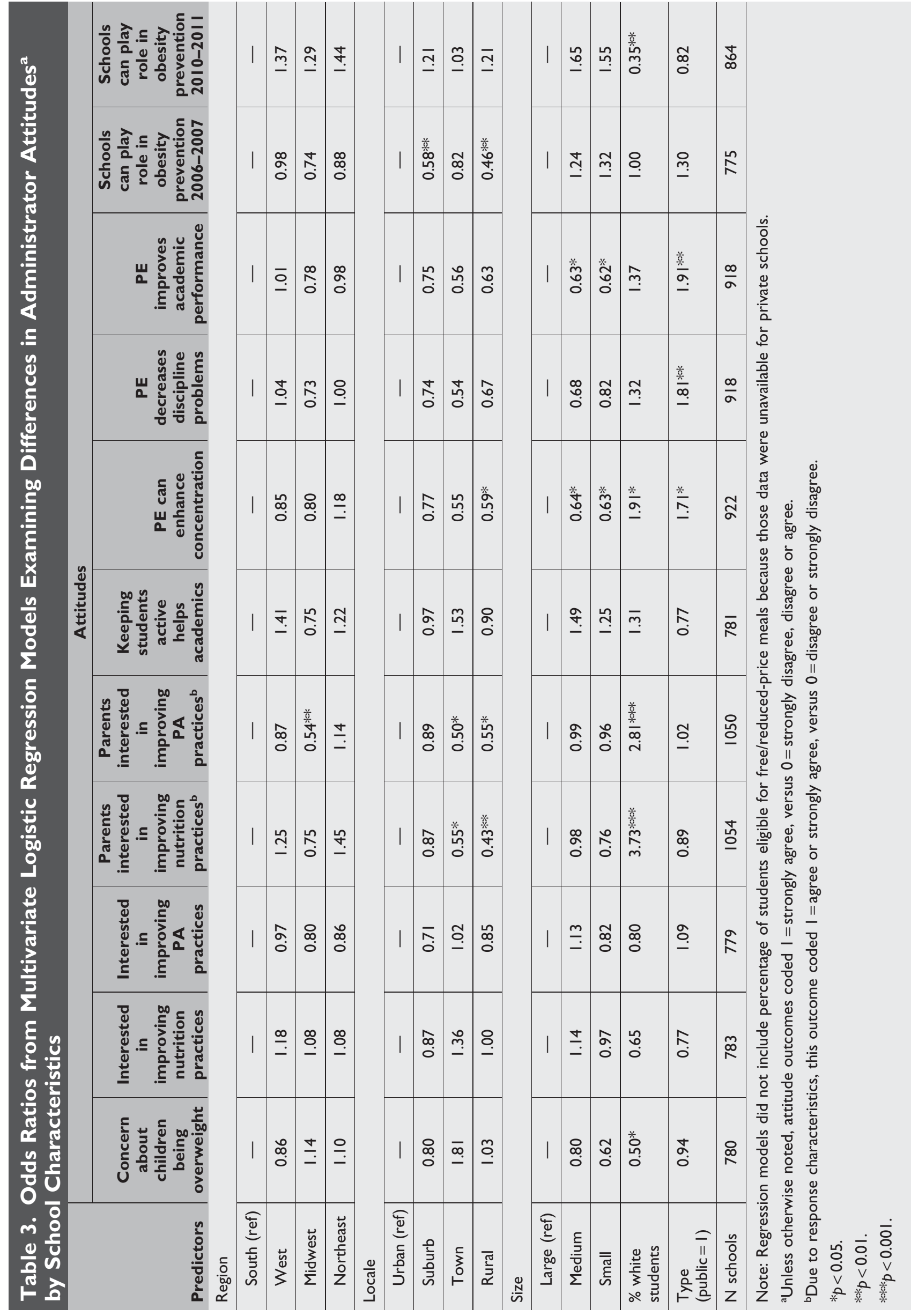


or "agree" (=1) versus "disagree" or "strongly disagree" $(=0)$ (see note in Table 3). As shown in Table 3, while there were generally few demographic differences, some notable patterns emerged. Administrators at schools in towns and rural areas were less likely than administrators at urban schools to perceive that parents were interested in improving nutrition practices at school. This effect held up even while also accounting for student race, which was also significantly associated with these attitudes. Administrators at schools with higher representation of white students were more likely to perceive that parents were interested in improving nutrition and physical activity practices. There were no significant differences in attitudes of administrators at public versus private schools other than the set of three items assessing the perceived value of $\mathrm{PE}$, which were all more likely to be strongly endorsed by administrators in public schools than in private schools. The regression models presented in Table 3 did not control for school socioeconomic status (SES), because student eligibility for FRPM was only available for public schools, not private schools. However, the regression models were recomputed using only public schools, with FRPM included as a covariate (results not shown in tables). FRPM was only associated with three outcomes: Administrators at lower-SES schools (i.e., higher FRPM eligibility) were more concerned about children being overweight [odds ratio $(\mathrm{OR})=3.37,95 \%$ confidence interval $(\mathrm{CI})=1.03$, $11.05, p<0.05]$ and more interested in improving school PA practices $(\mathrm{OR}=5.18,95 \% \mathrm{CI}=1.70,15.77, p<0.01)$, but less likely to perceive that parents were interested in improving nutrition practices $(\mathrm{OR}=0.27,95 \% \mathrm{CI}=0.10$, $0.71, p<0.01)$.

Finally, two additional logistic regression models (results not shown in tables) were computed to predict strong interest in promoting improved nutrition and PA practices at schools, accounting for all demographic covariates as noted above, including two attitude variables: Strong perceived concern about childhood obesity and strong agreement that schools can play a role in addressing childhood obesity. These models used data from the 2006-2007 school year. Again, administrator attitudes did not vary by school type nor by school demographics, but administrators were significantly more likely to be interested in improving nutrition practices where they also reported being concerned about children being overweight at their school $(\mathrm{OR}=21.15$, $95 \% \mathrm{CI}=10.93-40.93, p<0.001$ ), and where they believed that schools can play a role in addressing childhood obesity $(\mathrm{OR}=8.86,95 \% \mathrm{CI}=5.76-13.63, p<0.001)$. Likewise, administrator interest in improving PA practices was also associated with both of these variables, respectively $(\mathrm{OR}=26.23,95 \% \mathrm{CI}=13.02-52.82, p<0.001$ and $\mathrm{OR}=$ $6.84,95 \%$ CI $=4.40-10.64, p<0.001)$.

\section{Discussion}

Results showed widespread administrator agreement with a variety of statements regarding childhood obesity.
Importantly, most administrators recognized the value of quality PE in promoting outcomes, including improved concentration, better academic performance, and fewer discipline problems. Prior research has documented the perception among public elementary school administrators that competing time demands were a barrier to implementing PE $(23.4 \%$ of administrators agreed during 2006-2009), as were financial constraints (16.6\% agreed). ${ }^{25}$ Furthermore, PE not being a school priority has been associated with significantly lower likelihood of schools offering 150 minutes of PE per week, ${ }^{25}$ which is the amount recommended by the National Association for Sport and Physical Education (NASPE) ${ }^{26}$ and the CDC. ${ }^{27}$ Clearly, a variety of barriers to implementing PE (e.g., financial issues, scheduling demands) still remain, but awareness of the value of PE for improving academic outcomes does not appear to be lacking among administrators. Nevertheless, public school administrators were more likely to strongly agree with the value of PE than were private school administrators; this is consistent with data showing that private school students are less likely to receive adequate PE class time than are public school students. ${ }^{28}$ Thus, there may be a need for further education among private school administrators and school board members as to the value of hiring professionally trained and certified staff, as well as technical support for implementing quality PE programs.

As of the 2006-2007 school year, approximately threequarters of all school administrators agreed or strongly agreed that they were concerned about students at their school being overweight, with $20.9 \%$ indicating strong agreement on this issue. Although not released until 2008 (after the 2006-2007 survey period), nationally representative estimates for 2003-2006 showed that during that time period, $33.3 \%$ of children ages $6-11$ years were overweight or obese. ${ }^{29}$ Given the documented high prevalence of childhood obesity throughout the early 2000s, virtually all administrators worked in schools where obesity affected at least some of their students; thus, one might expect that more than one in five administrators would have been concerned about obesity. Considering the importance of concern in predicting health behavior practices, further efforts to inform school personnel regarding obesity prevalence, consequences, and prevention may be warranted. Indeed, regression models showed that where administrators reported concern about obesity affecting their students, they were also more interested in improving school practices. Likewise, research has shown that parents who are more concerned about obesity are more likely to engage in healthier behaviors, such as limiting screen time, increasing PA, and improving nutrition, ${ }^{30}$ thus demonstrating the link between health concern and behaviors.

Yet another construct that appears in many theoretically motivated investigations of health behavior is "perceived efficacy" (a.k.a., perceived behavioral control ${ }^{15,16}$ ) and this dimension - perceiving that schools have an important role to play in addressing obesity — was highly associated 
with administrators' interest in implementing changes. However, it is important to note that administrator interest in implementing changes may not necessarily be sufficient to promote change. Attention to school nutrition and PA practices has increased dramatically in recent years, and following the federal wellness policy mandate that took effect at the start of the 2006-2007 school year, ${ }^{22}$ nearly all US public school districts developed wellness policies to address nutrition and PA. ${ }^{31}$ However, the policies tended to be weak and fragmented and were not necessarily implemented at schools. ${ }^{31}$ Furthermore, nationwide data from public elementary schools showed very little change in either the school food environment ${ }^{32}$ or PE practices and PA opportunities ${ }^{33}$ from 2006-2007 to 2009-2010. Thus, awareness may not be sufficient to create change. The 2007 school stakeholder survey coordinated by Action for Healthy Kids found that two-thirds or more of school board members, administrators, and teachers believed that schools do not have adequate resources to improve school wellness. ${ }^{23}$ Principals noted the key barriers to school wellness as being competition from other school priorities (63\% agreed), lack of time in the school day (54\% agreed), and lack of resources (46\% agreed). ${ }^{23}$ Among 112 high school administrators nationwide, the most common challenges reported with regard to policy implementation in 2009 were lack of time or staff $(37 \%)$, cost $(33 \%)$, or implementation not being a priority $(26 \%) .{ }^{34}$ Thus, additional efforts and support, including financial resources, are essential for addressing implementation barriers.

For many of the attitude items assessed here, data were gathered during 2006-2007, approximately 6 years ago. Since that time, media attention regarding childhood obesity, as well as policy interventions such as the enactment of state laws pertaining to school nutrition and PA practices, ${ }^{35}$ and federal regulations (i.e., the federal wellness policy mandate, ${ }^{22}$ and the Healthy, Hunger-Free Kids Act of $2010,{ }^{36}$ which required improvements in school meals and other school food practices) reflect increased attention to the childhood obesity epidemic. It is possible that administrator attitudes have changed since the collection of these data. The wording of the survey item regarding the perception that "schools can play a role in addressing childhood obesity" changed slightly between the 20062007 and 2010-2011 school year item (i.e., removing reference to "[the problem of] childhood obesity"), thus formal statistical analyses were not conducted to test changes over time. Nevertheless, the percentage of all elementary school administrators strongly agreeing that schools can play a role in addressing childhood obesity increased from $40.8 \%$ to $53.1 \%$. This may be an artifact of the slight change in wording of the item, but it may also reflect strengthening of beliefs regarding the importance of the school environment. Encouragingly, the vast majority of administrators $(97.6 \%$ in 2010-2011) strongly agreed or agreed that schools can play a role in addressing childhood obesity.

Although subject to the typical limitations of survey methodology (e.g., response bias, social desirability bias), the use of a large nationally representative sample provides useful information to characterize the school environment nationwide and to provide insights into school administrators' attitudes and potential receptivity to intervention efforts. However, it is important to note that these data are cross-sectional, and thus it would be imprudent to conclude that changing certain attitudes will increase interest in implementing changes.

\section{Conclusions}

Given that most models of health behavior change posit that attitudes precede behavior, it may be reasonable to speculate that further educating school personnel about the issue of childhood obesity - as well as emphasizing the important role that schools can play in addressing childhood obesity - could promote further interest in and willingness to adopt changes in nutrition and PA practices. Suggested changes will be more compelling where based on solid science or credible recommendations from national authorities (e.g., competitive foods limits identified by the IOM; frequency and duration of PE recommended by NASPE and CDC). Nevertheless, financial constraints and time demands require balancing multiple priorities, and school administrators have many important issues to attend to in addition to student health, such as academic achievement and student safety. Financial support and technical resources for implementation will be essential in efforts to promote healthier school environments.

\section{Acknowledgments}

We thank Anna Sandoval, MPH, for assistance with the collection of survey data, and all of the school administrators who participated in the project. Research support was provided by the Robert Wood Johnson Foundation.

\section{Author Disclosure Statement}

The authors have no conflicts of interest to declare.

\section{References}

1. Ogden CL, Carroll MD, Kit BK, et al. Prevalence of obesity and trends in body mass index among US children and adolescents, 1999-2010. JAMA 2012;307:483-490.

2. Institute of Medicine. Accelerating Progress in Obesity Prevention: Solving the Weight of the Nation. National Academies Press: Washington, DC, 2012.

3. Institute of Medicine. Preventing Childhood Obesity: Health in the Balance. National Academies Press: Washington, DC, 2005.

4. Davison KK, Birch LL. Childhood overweight: A contextual model and recommendations for future research. Obes Rev 2001;2: 159-171.

5. Kumanyika S, Jeffery RW, Morabia A, et al. Public Health Approaches to the Prevention of Obesity (PHAPO) Working Group of 
the International Obesity Task Force (IOTF). Obesity prevention: The case for action. Int $J$ Obes Relat Metab Disord 2002;26: 425-436.

6. Moos RH. Social-ecological perspectives on health. In: Stone GC, Cohen F, Adler NE, eds. Health Psychology: A Handbook. JosseyBass: San Francisco, CA, 1979, pp. 523-547.

7. Stokols D. Establishing and maintaining healthy environments: Toward a social ecology of health promotion. Am Psychol 1992; 47:6-22.

8. Bronfenbrenner U. The Ecology of Human Development. Harvard University Press: Cambridge, MA, 1979.

9. Fox MK, Dodd AH, Wilson A, et al. Association between school food environment and practices and body mass index of US public school children. J Am Diet Assoc 2009;109:S108-S117.

10. Healthy Eating Research and Bridging the Gap. Influence of competitive food and beverage policies on children's diets and childhood obesity. 2012. Available at www.healthyeatingresearch .org/images/stories/her_research_briefs/RRCompFoods7-2012.pdf/. Last accessed April 2, 2013.

11. Kubik MY, Lytle LA, Story M. Schoolwide food practices are associated with body mass index in middle school students. Arch Pediatr Adolesc Med 2005;159:1111-1114.

12. Taber DR, Chriqui JF, Perna FM, et al. Weight status among adolescents in states that govern competitive food nutrition content. Pediatrics 2012;130:437-444.

13. Booth SL, Sallis JF, Ritenbaugh C, et al. Environmental and societal factors affect food choice and physical activity: Rationale, influences, and leverage points. Nutr Rev 2001;59:S21-S39.

14. Sallis JF, Owen N. Ecological models of health behavior. In: Glanz K, Rimer BK, Lewis FM, eds. Health Behavior and Health Education: Theory, Research, and Practice, $3^{\text {rd }}$ ed. Jossey-Bass: San Francisco, CA, 2002, pp. 462-484.

15. Fishbein M, Ajzen I. Belief, Attitude, Intention, and Behavior: An Introduction to Theory and Research. Addison-Wesley: Reading, MA, 1975.

16. Ajzen I, Fishbein M. Understanding Attitudes and Predicting Social Behavior. Prentice Hall: Englewood Cliffs, NJ, 1980.

17. Janz NK, Champion VL, Strecher VJ. The Health Belief Model In: Glanz K, Rimer BK, Lewis FM, eds. Health Behavior and Health Education: Theory, Research, and Practice, $3^{\text {rd }}$ ed. Jossey-Bass: San Francisco, CA, 2002, pp. 45-66.

18. Rosenstock IM. Historical origins of the Health Belief Model. Health Educ Monogr 1974;2:328-335.

19. Gortmaker SL, Peterson K, Wiecha J, et al. Reducing obesity via a school-based interdisciplinary intervention among youth: Planet Health. Arch Pediatr Adolesc Med 1999;153:143-151.

20. Bauer KW, Patel A, Prokop LA, et al. Swimming upstream: Faculty and staff members from urban middle schools in low-income communities describe their experience implementing nutrition and physical activity initiatives. Prev Chronic Dis 2006;3:A37.

21. Kubik MY, Lytle LA, Story M. Soft drinks, candy, and fast food: What parents and teachers think about the middle school food environment. J Am Diet Assoc 2005;105:233-239.

22. Child Nutrition and WIC Reauthorization Act of 2004, P.L. 108265, Section 204.

23. Action for Healthy Kids. Progress or Promises? What's Working For and Against Healthy Schools. Action for Healthy Kids: Skokie, IL, 2008. Available at www.actionforhealthykids.org/ for-schools/resources/files/progressorpromises.pdf/. Last accessed April 3, 2013.
24. Institute of Education Sciences. National Center for Education Statistics. Available at http://nces.ed.gov/. Last accessed April 2, 2013.

25. Slater SJ, Nicholson L, Chriqui JF, et al. The impact of state laws and district policies on physical education and recess practices in a nationally-representative sample of US public elementary schools. Arch Pediatr Adolesc Med 2012;166:311-316.

26. National Association for Sport and Physical Education. Physical Activity for Children: A Statement of Guidelines For Children Ages 5-12. National Association for Sport and Physical Education: Reston, VA, 2004.

27. Centers for Disease Control and Prevention. Youth physical activity: The role of schools. Available at www.cdc.gov/healthy youth/physicalactivity/toolkit/factsheet_pa_guidelines_schools.pdf/. Last accessed May 18, 2013.

28. Turner L, Chaloupka FJ, Sandoval A. School policies and practices for improving children's health: National elementary school survey results: school years 2006-07 through 2009-10. Vol 2. Bridging the Gap: Chicago, IL, 2012. Available at www.bridging thegapresearch.org/_asset/3t94yf/ES_2012_execsumm.pdf/. Last accessed April 2, 2013.

29. Ogden CL, Carroll MD, Flegal KM. High body mass index for age among US children and adolescents, 2003-2006. JAMA 2008;299: 2401-2405.

30. Moore LC, Harris CV, Bradlyn AS. Exploring the relationship between parental concern and the management of childhood obesity. Matern Child Health J 2012;16:902-908.

31. Chriqui JF, Schneider L, Chaloupka FJ, et al. School district wellness policies: Evaluating progress and potential for improving children's health three years after the federal mandate. School years 2006-07, 2007-08 and 2008-09. Vol 2. Bridging the Gap: Chicago, IL, 2010. Available at www.bridgingthegapresearch.org/ _asset/r08bgt/WP_2010_report.pdf/. Last accessed April 2, 2013.

32. Turner L, Chaloupka FJ. Slow progress in changing the school food environment: Nationally representative results from public and private elementary schools. J Acad Nutr Diet 2012; 112:13801389.

33. Turner L, Chaloupka FJ, Slater SJ. Geographic variations in elementary-school-based physical activity practices. J Sch Health 2012;82:307-310.

34. Budd EL, Schwarz C, Yount BW, et al. Factors influencing the implementation of school wellness policies in the United States, 2009. Prev Chronic Dis 2012;9:E118.

35. Trust for America's Health. F as in Fat: How Obesity Threatens America's Future 2011. Trust for America's Health: Washington, DC, 2011.

36. Summary of the Healthy, Hunger-Free Kids Act of 2010 (By Program). Available at www.fns.usda.gov/cnd/governance/ legislation/PL111-296_summary.pdf/. Last accessed April 1, 2013.

Address correspondence to: Lindsey Turner, PhD Research Scientist University of Illinois at Chicago Institute for Health Research and Policy 1747 W. Roosevelt Road, Room 558 Chicago, IL 60608

E-mail: lindseyt@uic.edu 